\section{Cytotoxic and Genotoxic potential of asbestos fibers from environmental outcrops}

SALVATORE VAIASICCA SR. ${ }^{1}$, SILVIA DI VALERIO ${ }^{1}$ LAURA CIANFRUGLIA $^{2}$, TATIANA ARMENI ${ }^{2}$, FRANCESCA FAZIOLI ${ }^{1}$, ANTONIO DOMENICO PROCOPIO $^{1}$ AND ARMANDA PUGNALONI $^{1}$

${ }^{1}$ Polithecnic University of Marche ; Molecular and Clinical Sciences - DISCLIMO

${ }^{2}$ Polithecnic University of Marche ; Scienze cliniche specialistiche ed odontostomatologiche - DISCO

Presenting Author: s.vaiasicca@staff.univpm.it

Exposure to elongate mineral particles from natural outcrops or synthetic origin such as asbestos fibers has a severe human health impact. In particular, asbestos exposure is causally associated to malignant pleural mesothelioma, one of the most lethal tumors in humans. Although the production and use of asbestos is today banned in many developed countries, people may still be exposed to asbestos, due to its presence in several structures such as public buildings, and the construction of residential areas in close proximity to former asbestos mines, factories, or soil containing natural asbestos. The disease burden associated with environmental asbestos exposure remains difficult to quantify and is still poorly investigated: a better chemical-physical and toxicity characterization of asbestos fibers present in the environment is therefore highly recommended.

The aim of the present study was to analyze the cytotoxicity and genotoxicity of two different natural asbestos fibers: Valmalenco Chrysotile from Central Alps, Italy (VM CHRY) and Erionite from Jersey Nevada, USA (JN ERI) using pulmonary human cells lines of mesothelial (MeT5A) and alveolar (A549) origin. UICC Chrysotile and UICC Crocidolite were included in our analysis as standard asbestos fibers.

Using the MTT assay, we observed a significative reduction of cell viability in both cell lines already after six hours of treatment. Detection of $\gamma-\mathrm{H} 2 \mathrm{~A}$.X histone highlighted the genotoxic character of both VM CHRY and JN ERI following $24 \mathrm{hrs}$ of fibers exposure. Furthermore, the decrease of Glutathione levels showing a increase of cellular stress.

DNA damage was also analyzed by the Comet assay, showing an increase of the tail length and tail moment parameters in both cell lines after $24 \mathrm{hrs}$ of exposition to different fibers in comparison to control cells. A major effect in MeT5A cells with respect to A549 was also observed after all treatments.

Taken together our findings testify the cytotoxic and genotoxic effects exerted in vitro by both VM CHRY and JN ERI fibers compared to the standard ones, suggesting the need of a careful surveillance related to particulate matter risks. Our next intent will be to deeper investigate the molecular mechanisms of cytotoxicity underlying asbestos exposure.

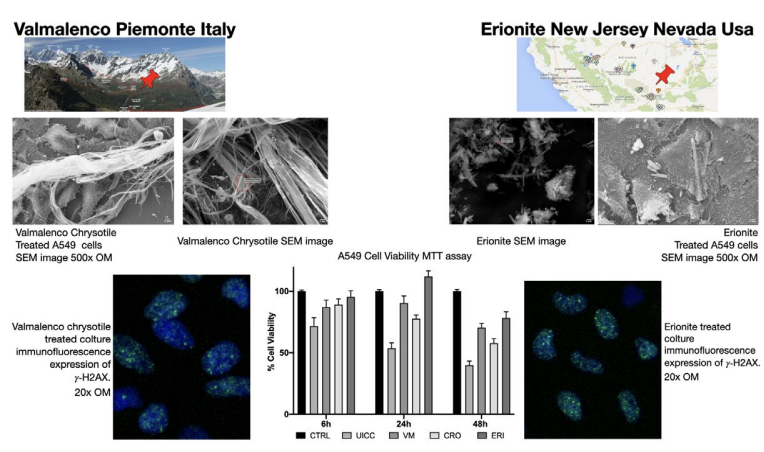

